sil toent

\title{
ИДЕЯ КОНСТИТУЦИОННОГО РАВНОПРАВИЯ ПУБЛИЧНЫХ СОБСТВЕННИКОВ И ЕЕ СООТНОШЕНИЕ С ЦИВИЛИСТИЧЕСКОЙ КОНЦЕПЦИЕЙ ЮРИДИЧЕСКОГО РАВЕНСТВА ВСЕХ СОБСТВЕННИКОВ
}

Аннотация: Работа представляет собой аналитическое исследование вопроса о главенствуючем юридическол принципе взаимоотношений публичных собственников в имущественной сфере. Автор на основе синтетического обобщения феноменологических характеристик публичной собственности, норм действующего в данной области законодательства России и практики его применения, различных научных точек зрения приходит к выводуо том, что характер взаимоотношений публичных собственников с иными собственниками не может определяться действием установленного в области гражданского права принципа юридического равенства участников оборота. Сопоставительный анализ норм конституциионого и гражданского законодательства, с учетом релевантных правовых позиций Конституциионного Суда РФ, показывает, что в основе взаимодействия в имущественной сфере публичных собственников находится иной по своей правовой природе принцип. Взаимодействие в имущественных отношениях публичных собственников между собой основывается на идее их конституционного равноправия, обусловленного федеративной природой Российского государства. Данный вывод следует из проведенного в работе сопоставительного анализа правовой позиции Конституиионного Суда Российской Федерации, сформулированной при рассмотрении дела, в котором оспаривалась конституциионность предусмотренного законодательством России порядка передачи государственного имущества субъектов РФ в федеральную собственность в результате разграничения полномочий по предметам совместного ведения Российской Федерации и ее субъектов.

Ключевые слова: Публичные интересы, публичная собственность, публичная власть, публичность, социокультурнье ценности, правовая аксиология, общество (нация), конституция, конституцчионое право, властеотношения. Abstract: This work presents the analytical research of the issue of dominant juridical principle of relations of public owners in property sphere. Based on synthetic generalization of phenomenological characteristics of public property, norms of Russia's legislation and practice of its application, and various scientific opinions the author comes to a conclusion that the nature of relations of public owners with other owners cannot be defined by the act of legal equality of participants of the transaction set in civil legislation. Comparative analysis of the norms of constitutional and civil legislation, with consideration of relevant legal positions of the Constitutional Court of the Russian Federation, demonstrates that the property relations of public owners are based on the principle that is different in its legal nature. Relations between the public owners are based on the idea of their constitutional equality under the federative nature of the Russian state. This conclusion derives from the comparative analysis of the legal position of the Constitutional Court of the Russian Federation formulated during a hearing of a case which argued the constitutionality of the transfer of state property of the constituents of the Russian Federation to federal property as a result of delimitation of authority on the subjects of joint competence of the Russian Federation and its constituents.

Keywords: Constitution, nation, legal axiology, socio-cultural values, public, public authority, public property, public interests, constitutional right, public relations.

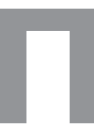

роблема определения главенствующего юридического принципа в правовых отношениях публичных собственников между собой и с остальными собственниками, не относящимися к разряду публичных, есть не что иное, как вопрос об их взаимодействии. Но о взаимодействии не всяком, а о правовом, т.е. юридически значимом и потому урегулированном нормами права. При этом такое взаимодействие, - оно же суть есть правовое общение, - имея характер ролевого взаимодействия его участни- 
ков, строится по принципу процесса обменного типа. Л. С. Мамут на этот счет отмечает: «Правовое общение - тот участок социального макропространства, на котором взаимодействующие друг с другом субъекты (контрагенты) насыщают свои разнообразнейшие потребности, всегда свойственные этим акторам. Вот raison d'etre правового общения. Будь иначе, правового общения просто не существовало бы. Другой вопрос, не менее принципиальный: каким конкретно способом эти потребности в нем (правовом общении) восполняются? Остается еще раз повториться: в правовом общении потребности субъектов (неодинаковье как по содержанию, так и по форме) удовлетворяются в процессе обмена столь же неодинаковыми, но социально равнодостойными (эквивалентными) благами и ролями (курсив наш. - М. Б.)» [9, с. 72].

Поскольку в правовом общении предметом обмена являются определенные социальные блага, постольку несложно предположить, что базис персонификации вообще любого субъекта права, так или иначе, представлен набором тех социальных благ, которые у него имеются и благодаря обмену которых на некоторые другие - необходимые ему, - такой участник правового общения имеет возможность удовлетворять свои определенные потребности, интересы.

Социальные блага, выступающие предметом обмена в рамках правового общения, со всей очевидностью могут быть охарактеризованы в качестве аксиологической доминанты этих обменных процессов: они являются центрами притяжения разнообразных социальных интересов - именно вокруг таких социальных благ или благодаря им происходит зарождение, преобразование и реализация интересов участников правового общения. Поэтому не будет являться ошибкой утверждение о том, что социальное благо, образующее базис персонификации для различных правосотворенных субъектов права, предопределено типом социальных интересов, которые вокруг этого блага или благодаря ему возникают, концентрируются, преобразуются и реализуются через взаимодействие различных субъектов права.

Простой пример. В ряду цивилистических концепций юридического лица одна из ведущих ролей принадлежит теории персонифицированного имущества: согласно этой теории юридическое лицо есть некоторый правосотворенный субъект гражданских правоотношений, олицетворяющий в имущественном обороте определенное имущество, которое ассоциировано с ним под соответствующим наименованием. Одним из самых убедительных аргументов данной теории юридического лица является довод о том, что контрагенты юридического лица, вступая в различные имущественные отношения с ним, усматривают возможность удовлетворения своих притязаний (в том числе и в случае нарушения юридическим лицом своих обязанностей) в праве обратить взыскание именно на имущество, имеющее правовую ассоциацию с данным юридическим лицом, т.е. принадлежащее ему на праве собственности или на ином законном основании, допускающем несение юридическим лицом самостоятельной имущественной ответственности. Соответственно, в имущественном обороте, когда речь идет о правосотворенных субъектах, реализующих в процессе обмена различными социальными благами свои частные интересы, базисом их персонификации, если говорить наиболее абстрактно, будет являться имущество: ведь именно имущество, находящееся у таких участников правового общения или потребное им, не только служит «пусковым» механизмом всего существующего в обществе имущественного (товарно-денежного) обмена, но и позволяет обособить одного участника правового взаимодействия от других.

Но может ли имущество (как феноменологическая категория) рассматриваться в качестве базиса персонификации для таких правосотворенных субъектов, которые в процессе правового общения реализуют публичные интересы? Думается, что нет. Ибо имущество, обремененное публичным интересом, в феноменологическом смысле уже совсем не то имущество, которое выступает предметом товарно-денежного обмена в традиционном его понимании. Если обратиться к нормам гражданского законодательства, регулирующим основные вопросы приобретения и прекращения прав государственной и муниципальной собственности, - а это ближайшие для примера случаи, касающиеся режима имущества, обремененного публичными интересами, - то становится видно, что соответствующие публичные образования, реализуя в имущественной сфере различные публичные интересы:

а) имеют ряд юридических возможностей для приобретения имущества в свою собственность, которых нет у «обычных» участников имущественного оборота и реализация которых происходит только в формате «власти и подчинения»: национализация, реквизиция, конфискация, изъятие земельного участка для государственных или муниципальных нужд, и ряд других. При этом уместным будет уточнить, что здесь и далее под «обычными» участниками имущественного оборота, при изначально весьма условном употреблении слова «обычные», понимаются натуральные персоны (физические лица) и правосотворенные персоны (хозяй- 
DOI: $10.7256 / 1811-9018.2015 .11 .16661$

При цитировании этой статьи сноска на доі обязательна

\section{Право и политика $11(191) \cdot 2015$}

ствующие субъекты), не реализующие в гражданском обороте публичные функции и публичные интересы: тем самым будет достигнута подчеркнутость существования не только объективных (фактических), но и формальных отличий между соответствующими субъектами - несмотря на то, что далеко не все ученые считают такие отличия поводом к дифференцированному рассмотрению участников гражданского оборота, и в подавляющем большинстве случаев публичные образования в гражданском праве рассматриваются в одном ряду с гражданами и юридическими лицами исходя из принципа их юридического равенства (в гражданском обороте);

б) несут определенные процедурные обременения в реализации своей собственнической правоспособности, которые не налагаются законом на «обычных» участников имущественного оборота: отчуждение имущества - по общему правилу, в порядке приватизации или на условиях концессионного соглашения; приобретение товаров, работ, услуг по договору - по общему правилу, по результатам процедур, предусмотренных законодательством Российской Федерации о контрактной системе в сфере закупок для обеспечения государственных и муниципальных нужд; и ряд других;

в) пользуются по сравнению с «обычными» участниками оборота определенными преимуществами и иммунитетами в части имущественной ответственности, в том числе в виде отсутствия законодательно предусмотренной возможности банкротства, бронирования изъятых из оборота и ограниченных в обороте видов имущества от взыскания кредиторов, возможности при определенных условиях отказаться от исполнения решений об имущественных взысканиях, постановленных надгосударственными юрисдикционными органами, и т.д.;

г) выступают в ряде случаев универсальными («по остаточному принципу») приобретателями имущества, когда на него отсутствуют другие претенденты из числа «обычных» участников имущественного оборота или когда такие претенденты отказались от приобретения соответствующего имущества в свою собственность либо отказались от права собственности на него: бесхозяйные вещи, находки, безнадзорные животные, клад, представляющий собой культурные ценности, а также выморочное имущество при наследовании.

Понятно, что одинаковый базис персонификации, избранный для всех участников имущественного оборота, создает известное удобство с точки зрения необходимости обеспечить безусловное действие принципа их юридического равенства в имущественном обороте.
Отсюда и распространенность в российской юридической науке концепции расщепленной юридической личности применительно к публичным образованиям, согласно которой в отношениях, регулируемых гражданским правом, такие публичные образования не реализуют публичную власть.

Однако же, нельзя забывать о том, что публичный собственник, вступая в акты правового общения с «обычными» участниками имущественного оборота, продолжает реализовывать публичные интересы (поскольку частных интересов - т.е. своих собственных, него нет и быть не может по определению); средой возникновения и развертывания публичных интересов при этом выступает публичная власть. Поэтому и реализация публичных интересов не может осуществляться вне связи с публично-властным началом соответствующих а́кторов. Подтверждением данного тезиса могут служить, по меньшей мере, уже те из поименованных в Гражданском кодексе РФ способов приобретения права государственной собственности, которые были названы выше и не могут быть реализованы иначе, чем в формате властеотношений. Сюда же следует отнести и такое правовое явление, как имущественные иммунитеты публичных образований, а равно возможность последних с соблюдением установленной для них компетенции (читай - с соблюдением пределов располагаемой ими в соответствии с законом публичной власти) ограничивать определенные виды имущества в обороте или объявлять их изъятыми из него, особенно если учесть, что такие ограничения или изъятия могут осуществляться по экономическим соображениям государственной значимости.

В контексте отмеченных выше случаев, когда в рамках имущественного оборота наиболее явно прослеживаются властные характеристики публичных собственников, допущение самой только возможности говорить о каком-либо мыслимом расщеплении их личности - в качестве персон, выполняющих властные функции (в публично-правовой сфере), и в качестве фиска (в имущественном обороте), - со всей очевидностью ведет в юридико-догматический тупик.

Ведь, действительно, если исходить из того, что юридическая личность публичных образований является расщепленной, то получится, что, например, властно-волевое решение об изъятии земельного участка для государственных нужд принимает одна персона (которая при этом никак не может «переступить» границу, оказавшись внутри круга участников гражданских правоотношений), а приобретение права государственной собственности на этот земельный 
участок происходит в пределах вещной среды другой персоны - притом, что эта последняя имеет с первой совершенно одинаковое наименование, но должна (по соображениям незыблемости и ненарушимости цивилистических догм) быть юридически уравнена с прежним собственником, у которого земельный участок оказался изъят. Не является ли подобная юридическая софистика сугубо спекулятивной, умозрительной? В чем ее практическая ценность? А главное, не опровергается ли эта концепция, являющаяся традиционной для современной отечественной цивилистики, положениями статьи 16 всё того же Гражданского кодекса РФ, которые касательно приведенного примера предусматривают, что убытки, вызванные изъятием земельного участка у прежнего собственника, как ни парадоксально, будут возмещаться не государствомвластителем (принявшим решение об изъятии), а государством-фиском (которое должно рассматриваться в данном случае как персона, не имевшая собственной воли на приобретение участка)?

Строгое следование идее юридического равенства участников имущественного оборота, когда в качестве субъекта, реализующего публично-властные функции, выступает должностное лицо, порождает еще больше вопросов о правомерности существования всевозможных концепций расщепления юридической личности публичных образований. Нетрудно представить ситуацию, когда должностное лицо, реализующее публично-властные функции, принимает в пределах своих полномочий решение, влекущее дальнейшее приобретение имущества в его частную собственность как гражданина (физического лица). Если при этом впоследствии выяснится и будет доказано, что данное должностное лицо допустило злоупотребление своими полномочиями, став конечным выгодоприобретателем от подобных действий, то, привлекая гражданина к уголовной ответственности даже после оставления им соответствующей должности, кто станет утверждать, что такой ответственности подлежит, будто бы, именно должностное лицо, а не сам этот гражданин, принявший в прошлом незаконное решение?

Получается, что в случае с «обычными» участниками имущественного оборота всевозможные концепции расщепления юридической личности (в том числе и с позиций различных видов юридической ответственности) не срабатывают. Но каковы же тогда основания к тому, чтобы считать столь незыблемой и абсолютной по своему значению идею формального (юридического) равенства участников имущественного оборота, если по отношению к «обычным» из них автономия воли субъекта, будучи одним из ключевых элементов концепции юридического равенства и свободы, сопряжена с наступающими именно для него имущественными последствиями, а в случае с публичными образованиями такого сопряжения не наблюдается? В чем же тогда состоит юридическое равенство участников имущественного оборота? И есть ли оно - это равенство, - в правовой реальности?

Отвечая на сформулированные вопросы, уместно будет привести некоторые суждения, высказанные по проблеме юридического равенства в современных исследованиях по общей теории и философии права. Так, Ю. Ю. Ветютнев по итогам анализа последовательного ряда довольно убедительных фактов, заключает: «Таким образом, в реальной правовой системе нет места для равенства, если понимать его как полное тождество статусов; равенство и неравенство всегда сочетаются в тех или иных пропорциях. При этом характерно, что современное право тяготеет к тому, чтобы возводить равенство в ранг универсальной ценности и общезначимого принципа, а неравенство при этом считается чем-то нежелательным и отодвигается в тень, хотя продолжает существовать фактически и имеет надежное формально-юридическое подкрепление» [3, с. 141]. Далее он также уточняет, что юридическое «равенство возможно лишь в относительно однородном сегменте общества» [3, с. 143]. Если следовать данной логике рассуждений, то можно утверждать, что частные собственники, как раз образующие такой относительно однородный сегмент общества, конечно же, могут обладать юридическим равенством в отношениях между собой; но постановка вопроса о юридическом равенстве между частными и публичными собственниками едва ли встретит столь же однозначный ответ.

Согласно воззрениям А. В. Малько и С. Ю. Суменкова также возможно утверждать, что одним из наиболее явных отступлений от принципа юридического равенства выступает такой феномен как правовой иммунитет, позволяющий его обладателю не подчиняться определенным, общим для всех законам [8, с. 107]. Наличие у публичных образований определенных имущественных иммунитетов уже отмечалось выше.

С учетом изложенного думается, что идея юридического равенства участников имущественного оборота сама по себе есть этико-юридический императив, недостижимый в реальной практике правового регулирования так же, как недостижимы идеалы правового государства и безусловного верховенства права. В случаях, когда в имущественный оборот вступают различные а́кторы, реализующие публично-властные 


\section{Право и политика 11 (191) • 2015}

функции и соответствующие публичные интересы, в действительности ни о каком юридическом равенстве между ними и «обычными» участниками имущественного оборота не может быть и речи: весь смысл идеи о юридическом равенстве всех без исключения субъектов правового общения сводится в данном случае, по существу, к определению справедливого и рационального баланса публичных и частных интересов в области имущественного оборота, т.е. к определению меры самоограничения публичной власти либо ограничения ее под воздействием различных социальных сил. И не более того.

Но есть возможность эту мысль продолжить и далее: пользуясь социо-реалистическим подходом к праву (иными словами, наблюдая за юридическим бытом), вполне уместно будет утверждать, что, подобно диалектическому взаимовлиянию вообще всего частного и публичного, каноны социального развития экономики (т.е. хозяйственной сферы жизни общества - имущественного оборота) во многом предопределяют возможные и допустимые границы дискретности публичной власти не только в тех случаях, когда соответствующие а́кторы вступают в конкретные акты правового общения с «обычными» участниками имущественного оборота, но и в тех, когда этими а́кторами применительно к сфере имущественного оборота совершаются акты правотворчества или юрисдикционного правоприменения. Таким образом, не только публичная власть, будучи определенным образом ограниченной или самоограниченной, воздействует на имущественный оборот в целях удовлетворения соответствующих публичных интересов, связанных с вещной средой публичного собственника, но и имущественный оборот воздействует на публичную власть, задавая и обусловливая рамки для ее ограничения или самоограничения с тем, чтобы она осуществлялась более или менее сбалансированно, не нанося ущерба своей дискретностью нуждам имущественного оборота и потребностям его развития.

Характерно, что суждения, подобные сформулированным выше, высказывают, с опорой на исследования дореволюционных российских юристов, и некоторые признанные отечественные цивилистысовременники, продолжающие при этом, что не может не удивлять, довольно упорно отстаивать идею о всеобщем юридическом равенстве в гражданском обороте, доводя ее, иной раз, до сакрализации. Так, авторы одного из широко известных учебников по гражданскому праву пишут, что исторический «опыт свидетельствует, что частное право и основные частноправовые начала (принципы), например такие, как неприкосновенность частной собственности или свобода договоров, нигде и никогда не действовали в “чистом виде”, наоборот, они всегда подвергались тем или иным публично-правовым ограничениям» [12, с. 56-57]. В конечном счете авторы учебника резюмируют: «Признание частного права состоит, следовательно, не в разрешении или исключении вмешательства государства в частные дела своих граждан, поскольку в ряде случаев оно, очевидно, является просто необходимым, а в ограничении этого вмешательства, в установлении для него строгих рамок и форм гражданским законом» [12, с. 57].

Соответственно, главное здесь заключается в том, что отсутствие в правовой реальности юридического равенства между публичными собственниками и «обычными» участниками имущественного оборота есть объективная данность, основанная на существовании социально обусловленного и, по всей очевидности, неустранимого приоритета важнейших публичных интересов перед интересами частными.

Осуществив, таким образом, более или менее подробный разбор проблемы юридического равенства в имущественном обороте «обычных» его участников и публичных собственников, выступающих как в виде поименованных в Гражданском кодексе РФ персон, так и опосредованно, становится возможным уверенно констатировать, что юридическое и фактическое отсутствие между ними формального равенства само по себе «снимает» с повестки вопрос о применимости для указанных категорий субъектов какого-либо единого, универсального базиса персонификации. В случае с «обычными» участниками имущественного оборота аксиологической доминантой, «вместилищем» их частных интересов, конечно же, выступает категория имущества как материального блага, служащего удовлетворению их разнообразных (своих собственных) потребностей. Не будь у таких участников определенного имущества и притязаний по поводу него, имущественный обмен (оборот) в принципе не мог бы состояться, как не могло бы состояться и правовое общение, этому фактическому имущественному обмену соответствующее. Существованием у «обычных» участников имущественного оборота именно такого базиса персонификации - имущества, - в частности, вполне могут быть объяснены и вообще появление, и весьма широкое распространение в циивилистике взглядов на юридическое лицо как на некоторое персонифици- 
рованное имущество, обращающееся в обороте под определенным наименованием и благодаря этому от других имуществ отграниченное.

В случае же с публичными собственниками (даже в тех ситуациях, когда они выступают в имущественном обороте в лице соответствующих хозяйствующих субъектов) осуществление ими публичных интересов предопределяет в качестве базиса их персонификации то социальное благо, вокруг которого и в «лоне» которого такие интересы концентрируются. С учетом неразрывной взаимосвязи публичных интересов, публичной власти и публичной собственности таким социальным благом, являющися базисом персонификации публичных собственников, может служить единственно лишь публичная власть - в совокупной взаимосвязи ее содержания, объема и направленности.

Наиболее отчетливо сформулированное выше суждение подтверждается в ходе анализа механизмов взаимодействия публичных собственников между собой - в контексте, разумеется, конституционно закрепленных принципов разделения властей и федеративного устройства Российского государства. К слову, именно эта часть социальных отношений собственности практически не исследуется в рамках науки гражданского права: в отношении вопроса о том, каким образом происходит реализация цивилистической догмы о юридическом равенстве применительно к области взаимоотношений публичных собственников, которые, если опереться на ключевые постулаты науки гражданского права, суть есть такие же собственники в отношениях между собой и с другими собственниками, как и собственники частные («обычные» участники имущественного оборота), цивилистика безмолвствует.

По всей видимости, подобному положению дел в современной науке гражданского права в немалой степени способствуют сохраняющиеся традиции советского периода ее развития, когда с учетом весьма специфичных принципов функционирования советской федерации в цивилистике активно отстаивался тезис о единстве фонда государственной собственности [2], автоматически устранявший из исследовательской повестки науки гражданского права соответствующие проблемы: считалось, что единым и единственным собственником государственных имуществ является Советское государство в целом (в единстве его «федеративного» центра и союзных республик), что и предопределяло исключение из предмета гражданскоправового регулирования каких-либо имущественных взаимоотношений такого сверх-собственника с союз- ными республиками и другими составными частями советской федерации - ведь эти отношения не предполагали юридического равенства между указанными субъектами, а при определенном ходе рассуждений вообще могли быть представлены как не поддающееся правовому нормированию взаимодействие публичного собственника с самим собой [6, с. 466-467].

Но не только в этом предполагаемом традиционализме просматриваются «скрытые» противоречия в интерпретации ключевых цивилистических догм, когда речь заходит о взаимодействиях сугубо между публичными образованиями: исключение из предметной области науки гражданского права проблематики такого взаимодействия, когда оно не строится явным образом на договорных началах, означает не что иное, как отступление от столь целенаправленно отстаиваемой идеи юридического равенства всех собственников и вообще всех участников имущественного оборота. Ведь в указанном контексте остается совершенно неясным, почему цивилистикой могут и должны охватываться вопросы, например, создания несколькими публичными образованиями объекта долевой собственности на основе договора, но совершенно должны быть исключены, к примеру, вопросы разграничения публичных имуществ: только потому, что федеральный законодатель предусмотрел возможность лишь субсидиарного применения к такому разграничению норм Гражданского кодекса РФ, да и то только в части, не противоречащей специальным федеральным законам? [13;5]

Соответственно, исключение из предметной области науки гражданского права проблематики имущественного взаимодействия, осуществляемого на внедоговорных началах между сугубо публичными образованиями, является довольно убедительным примером незримого отрицания в самой цивилистике провозглашенной в ее же рамках ключевой аксиологической доминанты имущественного оборота - юридического равенства всех его участников (вообще), а также всех собственников между собой (в частности).

В этом контексте кому-либо из цивилистов, кто однажды поставит цель устранить отмеченное незримое противоречие посредством методологических оснований гражданско-правовой науки, возможно, покажется отчасти даже парадоксальным тот факт, что вопрос об интерпретации принципов взаимоотношений публичных образований между собой по поводу разграничения публичной собственности и взаимной передачи друг другу соответствующих 
DOI: $10.7256 / 1811-9018.2015 .11 .16661$

При цитировании этой статьи сноска на доі обязательна

\section{Право и политика 11 (191) • 2015}

объектов стал предметом специального рассмотрения в Конституционном Суде РФ [10] - федеральном органе конституционного нормоконтроля, а не нашел прежде своего разрешения в рамках цивилистической теории или правоприменительной практики арбитражных судов. Особенно, если учесть содержание правовой позиции, сформулированной Конституционным Судом РФ по данному вопросу в п. 3.4. рассматриваемого постановления: «порядок безвозмездной передачи в федеральную собственность имущества, находящегося в собственности субъектов Российской Федерации, в связи с разграничением полномочий между органами государственной власти Российской Федерации и органами государственной власти субъектов Российской Федерации предполагает необходимость волеизъявления субъектов Российской Федераиии на такую передачу, достижение договоренностей между федеральными органами государственной власти и органами государственной власти субъектов Российской Федерации и не допускает принудительное отчуждение имущества, находящегося в собственности субъектов Российской Федерации, а потому не может рассматриваться как нарушающий конституционные правомочия субъектов Российской Федерации и гарантии государственной собственности субъектов Российской Федерации, в том числе вытекающие из статей 5 (часть 3 ), 8 (часть 2), 35 (части 2 и 3), 55 (часть 3) и 72 (пункт “г” части 1) Конституции Российской Федерации в их взаимосвязи (курсив наш. - М.Б.)» [10].

Эта правовая позиция, в случае ее интерпретации вне контекста предваряющих ее суждений, изложенных Конституционным Судом РФ в мотивировочной части рассматриваемого постановления, пожалуй, вполне могла бы произвести впечатление, будто бы с ее принятием Конституционный Суд России сделал значимый шаг к восстановлению на конституционном базисе целостности идеи юридического равенства всех собственников - для целей и в рамках имущественного оборота, т.е. в том смысле, в каком такое юридическое равенство представляет собой одно из ключевых начал гражданского законодательства. Однако, детальный анализ мотивировочной части рассматриваемого постановления Конституционного Суда РФ показывает, что в основе итоговой правовой позиции идея юридического равенства участников гражданского оборота, напротив, отсутствует. Более того, в контексте анализа правовой природы взаимоотношений публичных образований, складывающихся в процессе разграничения полномо- чий и в рамках обусловленного им соответствующего разграничения государственной собственности, Суд в п. 2.2. рассматриваемого постановления непосредственно указывает на то, что, по общему правилу, данные отношения гражданским законодательством, определяющим правовое положение участников гражданского оборота и регулирующим имущественные отношения, основанные на равенстве, автономии воли и имущественной самостоятельности их участников, не регулируются [10].

В ряду правовых оснований, послуживших предпосылкой для формулирования Конституционным Судом РФ итоговой правовой позиции, приведенной выше, находятся, таким образом, вовсе не цивилистические постулаты и догмы, а ключевые принципы федеративного устройства Российского государства, предполагающие, в том числе, самостоятельность публичных образований в отправлении публичной власти в законодательно очерченных для них пределах. С учетом существования имманентной взаимосвязи публичных интересов, публичной власти и публичной собственности очевидно, что самостоятельное отправление публичной власти в законодательно определенных для публичного образования пределах оказалось бы невозможным, не будь ему обеспечена и соответствующая самостоятельность в вопросах управления принадлежащим ему имуществом, неприкосновенность и защита этого имущества от произвольного изъятия - т.е. изъятия, осуществляемого без учета воли данного публичного образования и в ущерб реализуемым на его уровне публичным интересам.

Конституционный Суд России, хотя и не указал на данную имманентную взаимосвязь каким-либо специальным образом, видимо, всё же понимая, что таковая связь объективно имеет место быть, констатировал в п. 2.1. рассматриваемого постановления, что «необходимость разграничения государственной собственности между Российской Федерацией и субъектами Российской Федерации, предусмотренного непосредственно Конституцией Российской Федерации в качестве предмета их совместного ведения, предопределяется федеративным характером государства и разграничением полномочий между федеральными органами государственной власти и органами государственной власти субъектов Российской Федерации (курсив наш. - М.Б.) [10]; при этом там же указано, что «объем, пределы и особенности конкретных полномочий органов государственной власти Российской Федерации 
и органов государственной власти субъектов Российской Федерации по вопросам разграничения государственной собственности обусловлены особенностями государственной собственности, ее предназначением как экономической основы для осуществления функиий государства и реализации полномочий органов государственной власти Российской Федерации и органов государственной власти субъектов Российской Федерации (курсив наш. - М.Б.)» [10]. В этой связи Суд подытожил: «Таким образом, разграничение государственной собственности и передача имущества, находящегося в государственной собственности, осуществляемая в связи с разграничением полномочий между органами государственной власти Российской Федерации и органами государственной власти субъектов Российской Федерации, не должны быть произвольными (курсив наш. - М.Б.)» [10].

Развивая логику, лежащую в основании приведенного выше вывода, Конституционный Суд России в мотивировочной части анализируемого постановления также сформулировал следующие суждения:

- в п. 2.2.: федеральным законом, разграничивающим государственную собственность и устанавливающим порядок передачи имущества в результате разграничения публично-властных полномочий, должен быть обеспечен баланс интересов Российской Федерации и интересов ее субъектов; полномочия федеральных органов и органов власти субъектов РФ по разграничению государственной собственности и безвозмездной передаче имущества должны распределяться и осуществляться как находящиеся в совместном ведении - с тем, чтобы при принятии соответствующих решений обеспечивались бы учет и согласование интересов как Российской Федерации, так и ее субъектов [10];

- в п. 3.2.: безвозмездная передача государственной собственности предполагает необходимость согласованных действий соответствующих федеральных органов и органов власти субъектов РФ; тем самым федеральный законодатель, обеспечивая баланс интересов Российской Федерации и интересов ее субъектов, исключил возможность принятия федеральным органом исполнительной власти решения о безвозмездной передаче того или иного имущества, находящегося в собственности субъекта РФ, в федеральную собственность в одностороннем порядке [10].

Как видно из последовательного сопоставления приведенных выше суждений, Конституционный Суд РФ, формулируя общую правовую позицию в рамках анализируемого постановления, исходил из того, что принцип баланса интересов публичных образований в имущественных взаимоотношениях между собой, исключающий произвольный характер передачи объектов публичной собственности при разграничении полномочий, имеет прочное основание в модели федеративного устройства Российского государства. И, поскольку в рассматриваемом контексте российский федерализм означает, прежде всего, «вертикальное» разделение публичной власти между федеральным центром и составными частями государства, то Конституционный Суд России, акцентируя внимание в своей итоговой правовой позиции на необходимости достижения договоренностей и согласия между публичными образованиями по вопросам о взаимной передаче объектов публичной собственности, по существу, констатировал их конституционное равноправие - по меньшей мере, в этих вопросах, - основанное на одинаковом для них базисе персонификации: том объеме публичной власти и соответствующих ему публичных интересах, каковые ассоциированы с каждым из публичных собственников.

Иной подход Конституционного Суда России в этом вопросе, думается, противоречил бы вообще самому raison d'être федеративного государственного устройства, которое состоит в обеспечении сбалансированного функционирования и развития государства как единого целого при сохранении (или образовании) на его территории полицентрической системы политической публичной власти, где каждый из «центров» обладает известной самостоятельностью в управлении делами общества под известной же политической и юридической ответственностью.

При этом важно отметить, что конституционное равноправие публичных образований в имущественных взаимоотношениях между собой хотя, безусловно, и имеет некоторое внешнее сходство с юридическим равенством как принципом гражданско-правовых отношений, тем не менее, основывается при этом на сущностно ином социальном фундаменте. Конституционное равноправие публичных образований в этом контексте не предполагает в качестве обязательного атрибута обмен именно вещественными благами, а когда такой обмен всё же имеет место быть, то его цели всегда, так или иначе, сфокусированы не на самих обмениваемых объектах публичной собственности, а на том социальном благе, вокруг которого концентрируются соответствующие публичные интересы - т.е. на публичной власти, с целью более рационального отправления которой и производится взаимная передача требуемых для этого публичных имуществ. 
DOI: $10.7256 / 1811-9018.2015 .11 .16661$

При цитировании этой статьи сноска на dоі обязательна

\section{Право и политика $11(191) \cdot 2015$}

Библиография:

1. Анненков К. Система русскаго гражданскаго права. Т.2. 2-е изд., пересмотр. и доп.: Репринтное издание. - СПб.: Типография М. М. Стасюлевича, 1900. - 703 с.

2. Венедиктов А. В. Государственная социалистическая собственность / Отв. ред. Райхер В. К. - М., Л.: Изд-во АН СССР, 1948. - 839 c.

3. Ветютнев Ю. Ю. Аксиология правовой формы : монография. - М.: Юрлитинформ, 2013. - 200 с.

4. Винницкий А. В. Управление государственной собственностью на современном этапе: вопросы доктрины и законодательного регулирования // Право и политика. 2010. № 11. - С. 1909-1918.

5. Гражданский кодекс РФ (часть первая) от 30.11.1994 № 51-Ф3 (в ред. от 29.06.2015), п. 5 ст. 214 // С3 РФ. 1994. № 32 . Ст. 3301.

6. Гражданское право: учеб. в 3 т. Т. 1. - 6-е изд., перераб. и доп. / отв. ред. А. П. Сергеев, Ю. К. Толстой. - М.: ТК «Велби», Изд-во Проспект, 2006. - 776 с.

7. Коркунов Н. М. Лекции по общей теории права. - М.: РОССПЭН, 2010. - 520 с.

8. Малько А. В., Суменков С. Ю. Привилегии и иммунитеты как особые правовые исключения. - Пенза: Информационноиздательский центр Пензенского гос. ун-та, 2005. - 180 с.

9. Мамут Л. С. Правовое общение: очерк теории. - М.: НОРМА: ИНФРА-М, 2011. - 80 с.

10. Постановление Конституционного Суда РФ от 30.06.2006 № 8-П по делу о проверке конституционности ряда положений части 11 статьи 154 Федерального закона от 22 августа 2004 года № 122-ФЗ...в связи с запросом Правительства Москвы // С3 РФ. 2006. № 28. Ст. 3117.

11. Право собственности в СССР / Под ред. Ю. К. Толстого, В. Ф. Яковлева. - М., 1989. - 287 с.

12. Российское гражданское право: Учебник: в 2 т. Т. І: Общая часть. Вещное право. Наследственное право. Интеллектуальные права. Личные неимущественные права / Отв. ред. Е. А. Суханов. - 4-е изд., стереотип. - М.: Статут, 2014. - 958 с.

13. Федеральный закон от 22.08.2004 № 122-Ф3 (в ред. от 29.06.2015) «О внесении изменений в законодательные акты Российской Федерации и признании утратившими силу некоторых законодательных актов Российской Федерации в связи с принятием федеральных законов “О внесении изменений и дополнений в Федеральный закон «Об общих принципах организации законодательных (представительных) и исполнительных органов государственной власти субъектов Российской Федерации» и «Об общих принципах организации местного самоуправления в Российской Федерации»”, абз. 33 ч. 11 ст. 154 // С3 РФ. 2004. № 35. Ст. 3607.

14. Федеральный закон от 06.10.1999 № 184-Ф3 (с изм. и доп.) «Об общих принципах организации законодательных (представительных) и исполнительных органов государственной власти субъектов Российской Федерации», ст. 26.12 // С3 РФ. 1999. № 42. СТ. 5005.

15. Федорец М. Н., Авдеев Д. А. Конституционно-правовой поиск модели формы государственно-территориального устройства Российской федерации. // Право и политика. - 2014. - № 11. - С. 1661-1669.

16. Чеботарев Г. Н. Принцип разделения властей в государственном устройстве Российской Федерации. - Тюмень, 1997. - 218 с.

17. Чиркин В. Е. Публичное право и юридические лица // Право и политика. - 2015. - № 1. - С. 6 - 18.

18. Шахрай С.М. Роль решений Конституционного Суда Российской Федерации в становлении конституционной модели российского федерализма // Журнал зарубежного законодательства и сравнительного правоведения / Journal of foreighn legislation and comparative law. - 2012. - 2. - С. $27-36$.

19. Рудаков А.А. Кодификация конституционного законодательства // Административное и муниципальное право. - 2013. - 2. - С. 143 - 146. DOI: 10.7256/1999-2807.2013.02.8.

20. Остапович И.Ю. «Позитивное» нормотворчество в практике органов конституционного контроля России и зарубежных стран // Журнал зарубежного законодательства и сравнительного правоведения / Journal of foreighn legislation and comparative law. - 2014. - 5. - C. $797-804$.

\section{References (transliterated):}

1. Annenkov K. Sistema russkago grazhdanskago prava. T.2. 2-e izd., peresmotr. i dop.: Reprintnoe izdanie. - SPb.: Tipografiya M. M. Stasyulevicha, 1900. - 703 s.

2. Venediktov A. V. Gosudarstvennaya sotsialisticheskaya sobstvennost' / Otv. red. Raikher V. K. - M., L.: Izd-vo AN SSSR, 1948. $-839 \mathrm{c}$.

3. Vetyutnev Yu. Yu. Aksiologiya pravovoi formy : monografiya. - M.: Yurlitinform, 2013. - $200 \mathrm{~s}$.

4. Vinnitskii A. V. Upravlenie gosudarstvennoi sobstvennost'yu na sovremennom etape: voprosy doktriny i zakonodatel'nogo regulirovaniya // Pravo i politika. 2010. № 11. - S. 1909-1918.

5. Korkunov N. M. Lektsii po obshchei teorii prava. - M.: ROSSPEN, 2010. - $520 \mathrm{~s}$.

6. Mal'ko A. V., Sumenkov S. Yu. Privilegii i immunitety kak osobye pravovye isklyucheniya. - Penza: Informatsionno-izdatel'skii tsentr Penzenskogo gos. un-ta, 2005. - 180 s.

7. Mamut L. S. Pravovoe obshchenie: ocherk teorii. - M.: NORMA: INFRA-M, 2011. - $80 \mathrm{~s}$.

8. Fedorets M. N., Avdeev D. A. Konstitutsionno-pravovoi poisk modeli formy gosudarstvenno-territorial'nogo ustroistva Rossiiskoi federatsii. // Pravo i politika. - 2014. - № 11. - S. 1661-1669. 
9. Chebotarev G. N. Printsip razdeleniya vlastei v gosudarstvennom ustroistve Rossiiskoi Federatsii. - Tyumen', 1997. - 218 s.

10. Chirkin V. E. Publichnoe pravo i yuridicheskie litsa // Pravo i politika. - 2015. - № 1. - S. 6 - 18.

11. Shakhrai S.M. Rol' reshenii Konstitutsionnogo Suda Rossiiskoi Federatsii v stanovlenii konstitutsionnoi modeli rossiiskogo federalizma // Zhurnal zarubezhnogo zakonodatel'stva i sravnitel'nogo pravovedeniya / Journal of foreighn legislation and comparative law. -2012 . - 2. - C. $27-36$.

12. Rudakov A.A. Kodifikatsiya konstitutsionnogo zakonodatel'stva // Administrativnoe i munitsipal'noe pravo. - 2013. - 2. C. 143 - 146. DOI: 10.7256/1999-2807.2013.02.8.

13. Ostapovich I.Yu. «Pozitivnoe» normotvorchestvo v praktike organov konstitutsionnogo kontrolya Rossii i zarubezhnykh stran // Zhurnal zarubezhnogo zakonodatel'stva i sravnitel'nogo pravovedeniya / Journal of foreighn legislation and comparative law. - 2014. - 5. - C. $797-804$. 